\title{
Development of sentinel node localization and ROLL in breast cancer in Europe
}

\author{
Giovanni Paganelli • Alberto Luini • \\ Maddalena Sansovini • Paola Caroli • \\ Federica Matteucci
}

Received: 3 December 2014/ Accepted: 18 February 2015

(C) Italian Association of Nuclear Medicine and Molecular Imaging 2015

\begin{abstract}
The concept of a precise region in which to find the lymph nodes that drain the lymph directly from the primary tumor site can be traced back to a century ago to the observations of Jamieson and Dobson who described how cancer cells spread from cancer of the stomach in a single lymph node, which they called the "primary gland". However, Cabanas was the first in 1977 to realize the importance of this concept in clinical studies following lymphography performed in patients with penile cancer. Thanks to Morton's studies on melanoma in 1992, we began to understand the potential impact of the sentinel lymph node $(\mathrm{SN})$ on the surgical treatment of this type of cancer. The use of a vital dye (blue dye) administered subdermally in the region surrounding the melanoma lesion led to the identification of the sentinel node, and the vital dye technique was subsequently applied to other types of solid tumors, e.g. breast, vulva. However, difficulties in using this technique in anatomical regions with deep lymphatic vessels, e.g. axilla, led to the development of lymphoscintigraphy, started by Alex and Krag in 1993 on melanoma and breast cancer and optimized by our group at European Institute of Oncology (IEO) in Milan in 1996. Today, lymphoscintigraphy is still considered as the most reliable method for the detection of the SN. In 1996, a new method for the localization of non-palpable breast lesion called radioguided occult lesion localization (ROLL) was also developed at IEO. Retrospective and prospective studies have since
\end{abstract}

G. Paganelli $(\bowtie) \cdot$ M. Sansovini · P. Caroli · F. Matteucci Nuclear Medicine Unit, Istituto Scientifico Romagnolo per lo Studio e la Cura dei Tumori (IRST) IRCCS, Meldola, Italy e-mail: giovanni.paganelli@irst.emr.it

A. Luini

Division of Senology, European Institute of Oncology, Milan, Italy shown that the ROLL procedure permits the easy and accurate surgical removal of non-palpable breast lesions, overcoming the limitations of previous techniques such as the wire-guided localization. The purpose of this paper is to describe the evolution of SN biopsy and radioguided surgery in the management of breast cancer. We also include a review of the literature on the clinical scenarios in which SN biopsy in breast cancer is currently used, with particular reference to controversies and future prospects.

Keywords Sentinel node biopsy - Lymphoscintigraphy · ROLL $\cdot$ SNOLL $\cdot$ Breast cancer

\section{Introduction}

The sentinel lymph node (SN) technique and radioguided occult lesion localization (ROLL) of non-palpable tumors have changed the way we evaluate and treat early breast cancer, reducing the morbidity and improving the quality of life of patients. The concept of "sentinel lymph node" is intimately linked to the notion that, in the majority of patients, the metastatic spread of cancer through the lymphatic system follows a unidirectional, orderly and predictable pattern $[1,2]$. On the basis of this assumption, the histological evaluation of the "sentinel node", i.e. the first lymph node that drains the lymph directly from the primary tumor, enables us to exclude the presence of malignant cells in other lymph nodes. Therefore, the status of the SN is capable of accurately predicting the pathological state of the subsequent regional lymph node stations. Cabanas was the first to understand the importance of this concept in 1977 in clinical studies performed on patients with penile cancer [3]. He not only managed to locate the SN (which he mistakenly believed to be located in a fixed anatomic site), but 
also observed a correlation between disease status and lymph node involvement, concluding that if the SN biopsy was negative, there would be no need to perform further surgical treatments.

During the 1990s, the potential impact of SN on the surgical treatment of cancer was further demonstrated in the clinical setting $[4,5]$ by the use of a vital dye (blue dye) administered subdermally in the region surrounding the lesion. However, the low success rate of this method led to the development of lymphoscintigraphy, subsequently acknowledged as the most reliable method for SN detection. Alex and Krag [6] were the first to publish results on lymphoscintigraphy in melanoma and breast cancer in 1993, after which the technique was optimized by our group at the European Institute of Oncology (IEO) in Milan in 1996-1998 [7, 8]. Since then, the procedure has been used in thousands of breast cancer patients throughout Europe. The first randomized trial comparing total axillary dissection with SN biopsy was performed by Veronesi and co-workers [9] on patients with breast cancers $<2 \mathrm{~cm}$ in size. After preliminary results favoring SN biopsy were made known, new patients refused to be randomized and the study was forced to close with a recruitment of 516 patients (257 in the SN biopsy + total axillary dissection arm vs. 259 in the SN biopsy only arm). Of the 257 patients in the axillary dissection group, $32.3 \%$ of patients had a positive $\mathrm{SN}$ and 174 had a negative sentinel node $(67.7 \%)$. Of the 259 patients in the SN group, 92 had a positive SN $(35.5 \%)$, and 167 had a negative SN (64.5\%). The IEO results were further confirmed by those of the NSABP B-32 study $[10,11]$, i.e. sentinel lymph node biopsy accurately predicted axillary status in $96.9 \%$ of patients, with a falsenegative rate of $8.8 \%$. Moreover, post-operative morbidities were much less frequent in the sentinel node group. In 1996, in addition to the SN study for the optimization of the lymphoscintigraphy technique, a new method for the localization of non-palpable breast lesions called ROLL (radioguided occult lesion localization) was also developed by our group $[12,13]$.

Wire-guided localization (WGL) has been the standard technique for many years to localize non-palpable lesions [14]: the surgeon uses a thin, hooked wire inserted under ultrasound or stereotactic guidance into the lesion to identify and remove it. However, numerous studies [15, 16] have reported a high rate of positive margins after wire localization (between 14 and $47 \%$ ) resulting in the need for re-operation or in a greater incidence of local recurrence.

In the ROLL technique, a radioactive tracer $\left({ }^{99 \mathrm{~m}} \mathrm{TcMAA}\right)$ is injected into the tumor under stereotactic or ultrasound guidance the day before surgery. A handheld gamma probe similar to that of SN biopsy is used to guide intra-operative lesion identification and surgical resection [12]. Several publications have suggested that this technique has led to decreased positive margin rates, a lower incidence of re-operation and more accurate surgical excision [17-21].

In the present article, we report some of the most important developments made in the fields of SN biopsy and ROLL technique in breast cancer.

\section{SN methodological aspects}

Despite its widespread use, there is still no general consensus on the correct methodology of the SN biopsy procedure and numerous open questions remain to be resolved, e.g. kind of tracer to use, route of injection, or correct imaging technique (static, SPECT or SPECT/CT).

\section{Radiotracers}

The radiopharmaceutical used for SN biopsy must meet the following requirements:

1. It must permit the visualization of the lymphatic channels leading from the site of administration to the corresponding lymph node.

2. It must be retained in the first lymph node(s) encountered along such lymphatic pathways. Intranodal retention is due to the macrophages lining the sinusoid spaces of lymph nodes whose main function is to clear the affluent lymph of particulate matters through an active, saturable phagocytosis process [7, 22].

The efficient uptake of radiolabelled particles in lymph nodes is dependent on the size of the particles, the surface charge and on a preliminary reaction of opsonization that activates membrane receptors on the macrophages and consequently phagocytosis of the radiocompound [7, 2227]. These characteristics are shared by different formulations, both inorganic $\left({ }^{198} \mathrm{Au}\right.$-colloid, ${ }^{99 \mathrm{~m}} \mathrm{Tc}$-antimony sulfide, ${ }^{99 \mathrm{~m}} \mathrm{Tc}$-sulfur colloid, ${ }^{99 \mathrm{~m}} \mathrm{Tc}$-stannous fluoride, ${ }^{99 m}$ Tc-rhenium sulfide) and organic (micro-or nanocolloid human albumin). After interstitial administration, the colloidal particles pass into the lymphatic circulation with a speed that is inversely proportional to particle size [25, 28].

In our experience, the ideal tracer is composed of particles between 100 and $200 \mathrm{~nm}$ in size to obtain the best compromise between speed of drainage and accumulation in the sentinel node. In fact, colloidal tracer particles smaller than $50 \mathrm{~nm}$ drain rapidly into the lymphatic vessels but also pass easily into second- and third-level lymph nodes. On the other hand, tracers composed of particles $>300 \mathrm{~nm}$ do not drain easily into the lymphatic system, making it difficult to visualize the SN. In our first series of 240 consecutive patients, the mean number of lymph nodes visualized using radiocolloid particles ranging in size 
between 15 and $50 \mathrm{~nm}$ was 2.1 (SD 1.1), 1.6 (SD 0.8) for tracer particles $\leq 80 \mathrm{~nm}$ and 1.3 (SD 0.5) for larger particles [7]. Colloidal tracer particles of 100-200 nm are not commercially available and currently the most widely used radiopharmaceutical in the USA is the technetium-labeled sulfur colloid in a non-filtered (with particles ranging from about 15 to $5000 \mathrm{~nm}$ ) or filtered form.

In Europe, the majority of Nuclear Medicine Centers use human serum albumin particles of $40-100 \mathrm{~nm}$ $(95 \%<80 \mathrm{~nm}$ ), whereas antimony trisulfide (range $3-30 \mathrm{~nm}$ ) is commonly used in Australia and Canada.

With regard to the timing of preoperative scintigraphy, it should be taken into account that the amount of marked colloidal particles detectable in the SN $15-18 \mathrm{~h}$ after injection is low; in fact, only $1 \%$ of the subdermally injected activity remains in the lymph node and this percentage is further reduced if the dose is administered via peritumoral injection [7]. In general, lymphoscintigraphy performed in the afternoon prior to surgery (15-18 $\mathrm{h}$ before surgery) leads to optimal lymphatic drainage for radiocolloids of any particle size. Conversely, if only smaller radiocolloids are available, it is better to perform the imaging study and surgical procedure on the same day to avoid the colloids draining to second- or third-echelon nodes before surgery. A colloid labeled with $99 \mathrm{mTc}$ is used for the ROLL technique: a review of the literature [29] reveals that macro-aggregates are the tracer of choice in about $67 \%$ of cases and 99mTc-nanocolloids in the remaining $33 \%$, without, however, any difference in the detection rate of lesions during surgery.

\section{Methods of inoculation}

The optimal injection approach has been much debated over the past 18 years. The different methods proposed can be divided into two main categories: deep injection (intratumoral, peritumoral or subtumoral) and superficial (intradermal, subdermal, subareolar or periareolar). Multiple studies have been carried out to compare outcomes using the different injection methods, the majority showing equivalent rates for the detection of $\mathrm{SN}$, whereas a few reported that periareolar and subareolar injections are slightly better than peritumoral injection. Only one study [30] observed a significant difference between superficial and deep injection. Two prospective randomized trials on inoculation methods have been published to date [31, 32] without, however, reaching definitive conclusions. Povoski et al. reported that the rate of identification of the SN was higher with intradermal injection, while Rodier concluded that periareolar injection was the most effective route of administration because of the $99.11 \% \mathrm{SN}$ detection rate and the high concordance (95.56\%) between blue dye and radiotracer. Data from a study conducted by our group [7] comparing intradermal and peritumoral injection revealed no significant differences in the SN detection rate, the only variation worthy of note being the longer time required for $\mathrm{SN}$ visualization by peritumoral administration.

Other factors should be considered when deciding on the injection method. One major advantage of superficial injection is that it is easy to perform and results in less interference with scintigraphic imaging. Moreover, this method does not require ultrasound guidance, even in cases of non-palpable breast cancer. Deep injections are difficult to perform in such patients and often ultrasound or stereotaxic guidance, which also facilitate the detection of extra-axillary nodes.

We believe that both deep and superficial injection approaches are valid techniques and often complementary; combinations of injection techniques (either peritumoral and subareolar/periareolar injections [33] or subdermal/ peritumoral injection [34]) may improve detection accuracy and decrease false-negative rates (FNR). This is supported by the results from Suami et al.'s [35] human cadaver study of breast lymphatic anatomy which showed that although the majority of superficial lymph vessels of the breast drain to only one sentinel node some show alternative lymphatic drainage. Our current approach is to use subdermal injection if the tumor is localized superficially and peritumoral administration when the lesion is located deeper within the mammary gland.

\section{Imaging}

The acquisition of images after administration of the radiopharmaceutical is considered an indispensable part of the process of identification of the SN. Such images, in fact, provide basic information on pathways that are unobtainable when only the probe is used. The images acquired after the injection of the colloid greatly enhance the accuracy of the surgical resection [36]; this is especially true when the $\mathrm{SN}$ is localized near the site of injection of the tracer, or when extra-axillary lymph nodes are involved, e.g. internal mammary chain (IMC) nodes. The time required to perform the preoperative scintigraphy varies on the basis of the tracer used, ranging between 15 and 90 min after injection [37-39], while surgery can be delayed for up to $16-18 \mathrm{~h}$ after injection with radiocolloids of 200-1000 nm [40].

It has been seen that both SPECT and SPECT/CT are useful in specific conditions [41-44]; EANM guidelines [45] recommend the use of tomographic imaging in cases of non-visualization of SN in planar images, especially in obese patients, in the presence of extra-axillary drainage or in sites that are difficult to visualize, e.g. multiple drainage sites, IMC nodes, intramammary lymph nodes, contralateral axilla nodes or surgically resected sites. The use of 
SPECT/CT is also advisable when conventional images are difficult to interpret, for example in the event of contamination or when $\mathrm{SN}$ is located near the site of injection.

Indications and controversies

The localization and biopsy of the SN represent the "standard of care" for the staging of axillary lymph nodes in breast cancer patients. These procedures have also replaced axillary lymph node dissection (ALND), performed routinely in the past, in women with stage I-II breast cancer with no evidence of axillary lymph node involvement $[7,45,46]$.

Patients with negative SN biopsy do not require ALND, as concluded by American Society of Clinical Oncology guidelines [47] on the basis of results from large randomized trials conducted in both Europe and the US [48-52] (Table 1). However, ALND remains the standard treatment for patients with axillary metastases identified by $\mathrm{SN}$ biopsy and is also performed in cases in which the $\mathrm{SN}$ is not identified during surgery.

\section{Minimal lymph node involvement}

One area that requires further investigation is that of the detection of micrometastases and/or isolated tumor cells (ITCs) in SN. Micrometastases are defined as a tumor deposit between 0.2 and $2.0 \mathrm{~mm}$ and with more than 200 cells, while ITCs are clusters of cells no $>0.2 \mathrm{~mm}$ in size or with fewer than 200 cells [53].

Between 2001 and 2010, the International Breast Cancer Study Group (IBCSG) 23-01 trial recruited women with primary breast cancer $\leq 5 \mathrm{~cm}$ and only $\mathrm{SN}$ micrometastatic disease from 27 institutions. The women were randomized to SN only or standard complete ALND. At a median follow-up of 5 years, the axillary recurrence rate was $<1 \%$ in both arms and survival outcomes were similar in the ALND and SLNB-alone-groups (DFS: $84 \%$ vs $88 \%$, respectively) [52]. Comparable results were obtained in the multi-institutional ACOSOG study [51] which evaluated the safety of not performing ALND in a subgroup of patients with $\mathrm{SN}$-detected micrometastatic disease. Patients were randomized to either complete ALND or observation.

Results showed that there was no difference in local recurrence or disease-free survival between patients undergoing observation and ALND at a median follow-up of 6.3 years. Five-year overall survival in the axillary dissection arm was $91.8 \%$ [95\% confidence interval (CI): $89.1-94.5 \%$ ] vs. $92.5 \%$ in the observation arm (95\% CI: 90.0-95.1\%). Five-year disease-free survival was $82.2 \%$ in the axillary dissection arm (95\% CI: 78.3-86.3\%) vs. $83.9 \%$ in the observation group (95\% CI: 80.2-87.9\%).
The 2011 St. Gallen Consensus Conference [54] concluded that micrometastases in the SN are not an indication for ALND, irrespective of the type of breast surgery performed.

\section{Ductal carcinoma in situ (DCIS)}

DCIS metastasizes to axillary lymph nodes in a very small proportion of patients (1-2\% of cases) and for this reason the National Cancer Institute does not recommend SN biopsy [55]. However, the diagnosis of DCIS is often subject to sampling error, and a certain percentage of patients with an initial diagnosis of DCIS are actually found to have invasive carcinoma with axillary metastases after surgery. The role of SN biopsy in the management of DCIS is much debated: some authors recommend its use because of the somewhat alarming rate of diagnostic errors [56, 57], while others advise against it on the basis of the low incidence of lymph node involvement in patients with true DCIS [58]. A meta-analysis of 22 published studies revealed that the incidence of SN metastases in patients with a preoperative diagnosis of DCIS was $7.4 \%$ (95\% CI 6.2-8.9), significantly higher than that in patients with a definite post-operative diagnosis of DCIS (3.7 \%) [59]. SN biopsy is currently recommended in patients with DCIS submitted to mastectomy; in patients in whom breast conservation is planned, SN biopsy can be performed later if invasion is detected in a surgical specimen. Nevertheless, some centers opt to perform SN biopsy in DCIS patients because they sustain that wide local excision may alter lymphatic drainage, especially to IMCs, making a subsequent SN biopsy difficult [60].

\section{SN biopsy after prior breast or axillary surgery}

The SN method is normally restricted to women who have not already undergone surgery as it is important to have an intact lymphatic system for optimal drainage. However, there is evidence to suggest that SN biopsy can also be performed after either conservative or radical surgical treatment: Port et al. [61], in their study of 117 patients previously submitted to surgery, reported an SN detection rate of $55 \%$ which was directly proportional to the number of lymph nodes removed during the first intervention, and was more successful after a previous SLN biopsy than a previous ALND (74 vs. $38 \%$ ). In this series, although there were no cases of locoregional recurrence at a mean follow-up of 2.2 years, $5 \%$ of patients developed distant recurrence. Cox et al. [62] reported an SN detection rate of $80 \%$ in a series of 56 patients, with no axillary recurrence after 2 years. The same group subsequently published data on patients who had previously undergone ipsilateral lymph node dissection, this time reporting a detection rate of only $29 \%$ [63]. 
Table 1 Main randomized trials comparing SLNB vs SLNB + ALND

\begin{tabular}{|c|c|c|c|c|c|}
\hline Trial & Year & Comparison & Population & Median FU (months) & Recurrence \\
\hline \multirow[t]{2}{*}{ GIVOM [48] } & \multirow[t]{2}{*}{2008} & SLNB + ALND (if SLNB positive) & 352 & \multirow[t]{2}{*}{56} & 5 years DFS $89.9 \%$ \\
\hline & & SLNB + ALND & 345 & & 5 years DFS $87.6 \%$ \\
\hline \multirow[t]{2}{*}{ NCT00970983 [49] } & \multirow[t]{2}{*}{2010} & SLNB + ALND (if SLNB positive) & 257 & \multirow[t]{2}{*}{102} & 5 years DFS $89.9 \%$ \\
\hline & & SLNB + ALND & 476 & & 5 years DFS $89.9 \%$ \\
\hline \multirow[t]{2}{*}{ NSABP [50] } & \multirow[t]{2}{*}{2010} & SLNB alone & 2011 & \multirow[t]{2}{*}{95.6} & DFS $16.7 \%$ \\
\hline & & SLNB + ALND & 1975 & & DFS $15.9 \%$ \\
\hline \multirow[t]{2}{*}{ ACOSOG Z0011 [51] } & \multirow[t]{2}{*}{2011} & SLNB alone & 446 & \multirow[t]{2}{*}{75} & 5 years DFS $83.9 \%$ \\
\hline & & SLNB + ALND & 445 & & 5 years DFS $82.2 \%$ \\
\hline \multirow[t]{2}{*}{ IBCSG 23-01 [52] } & \multirow[t]{2}{*}{2013} & ALND only (after SLNB) & 464 & \multirow[t]{2}{*}{60} & 5 years DFS $84.4 \%$ \\
\hline & & No ALND (after SLNB) & 467 & & 5 years DFS $87.8 \%$ \\
\hline
\end{tabular}

The experiences reported in the literature suggest that distant metastases are more frequently detected than axillary lymph node recurrence when SN biopsy is performed as second surgery, thus lessening its impact from a prognostic or therapeutic point of view.

\section{Pregnancy}

There are obvious difficulties in the management of breast cancer during pregnancy, e.g. how to evaluate nodal status. Although this was not a problem when axillary dissection was the standard staging procedure, careful assessment of the risks and benefits of the $\mathrm{SN}$ technique is required in this population. The technique in both melanoma and breast cancer uses a standard dose of $11-111 \mathrm{mBq}$ of $99 \mathrm{mTc}-$ nanocolloids. In pregnant patients, the dose absorbed by the fetus is about $0.43 \mathrm{cGy}$ [64] and the risk of embryonic or fetal genetic defects ranges from 0.024 to $0.099 \%$ per cGy [65], whereas the lowest threshold for fetal teratogenicity has been estimated at 5 cGy [66]. Although studies conducted on pregnant women [64] suggest that the radionuclide does not put the fetus at risk and that the technique can be used safely in this population, there are still too few data to confirm this. For this reason, written informed consent must be obtained from the patient before the procedure can be undertaken.

\section{Sentinel lymph node of IMNS}

The SN technique allows for a better assessment of lymph node status in IMNs which are generally evaluated in the standard surgical procedure. The presence of IMN metastases is a poor prognostic factor [67] and is correlated with a higher incidence of distant metastases and reduced survival $[68,69]$. The involvement of IMNs is more frequent in tumors located in inner breast quadrants, even in cases of subcentimeter lesions. The risk of distant metastases increases by $30 \%$ in inner quadrant lesions, with a $20 \%$ higher mortality; in particular, the risk of metastasis to IMN is associated with age (decreases with increasing age), primary tumor size and the presence of axillary metastases [70].

From a methodological point of view, intraparenchymal or peritumoral administration of a $0.2-0.3 \mathrm{ml}$ volume of $15-18 \mathrm{MBq}$ of $99 \mathrm{mTc}$ albumin colloids is required to visualize IMNs. This method of administration permits at least one IMN to be visualized in $60 \%$ of tumors, whereas intra/subcutaneous administration is only effective in $1-2 \%$ of cases. Furthermore, the probability of visualizing IMNs increases if the injection is made in the inner quadrants of the breast. However, it must be underlined that tumors located deep within the breast, especially in inner quadrants, probably drain to IMNs, making it necessary to perform lymphoscintigraphy to localize the SN [71].

The role of IMN biopsy remains to be defined. There is some evidence that the mapping of IMNs improves staging and facilitates therapeutic decision making (radiotherapy or systemic therapy), but this has yet to be confirmed [72].

\section{ROLL and SNOLL}

SN biopsy and ROLL can be used in combination (SNOLL) for cancers or high-grade infiltrating ductal atypia. A recent review [73] analyzed the results from seven studies evaluating 983 patients with non-palpable breast cancer. The rate of complete resection with negative margins ranged from 82 to $90.5 \%$, while $2-12 \%$ of patients required re-operation.

The authors concluded that, although SNOLL is a feasible, safe and effective procedure for the treatment of nonpalpable breast cancers, multicenter randomized trials are needed to validate the methodology before it can be approved as a standard of care in this type of tumor. 
New non-radioactive tracers

SN biopsy and ROLL/SNOLL require radioactive substances, thus restricting their use to centers with a nuclear medicine department. This limiting factor probably explains why, despite the increased incidence of breast cancer, the use of SN biopsy has reached a plateau of about $60 \%$ in developed countries that have access to this procedure [74], decreasing to $5 \%$ in China and the rest of the world [75]. Recent years have seen the development of alternative methods that involve the use of non-radioactive substances. A recent systematic review by Ahmed et al. [76] analyzed 21 studies on new molecules for SN biopsy, including fluorescent indocyanine green (ICG), contrastenhanced ultrasound (CEUS) using microbubbles, or superparamagnetic iron oxide nanoparticles (SPIO). The authors concluded that the new methods were not superior to $\mathrm{SN}$ biopsy performed with traditional molecules in terms of the $\mathrm{SN}$ detection rate.

Thill et al. [77] recently carried out an international prospective, multicentre, non-randomized paired equivalence study on 150 patients with histologically confirmed breast cancer to evaluate the TSentiMag ${ }^{\circledR}$ technique, a non-radioactive detection system that magnetically marks the location of lymph nodes prior to their surgical removal and subsequent analysis. The authors detected 291 SNs in 150 patients using both $99 \mathrm{mTc}$ and TsentiMag $^{\circledR}$; the nodal detection rate was $91.8 \%$ for the radioisotope and $97.3 \%$ for the SPIO tracer, with a nodal concordance of $98.5 \%(263 / 267$; CI 96.5-99.5\%) and a reverse nodal concordance of $92.9 \% \quad(263 / 283$; CI 89.5-95.5\%). It was concluded that magnetic SN biopsy was comparable with the standard radioactive method in terms of ease of execution, safety and efficacy. All of the new technologies require further evaluation in randomized controlled trials prior to their introduction into clinical practice.

\section{Conclusion}

SN biopsy has gradually become the standard of care for a number of solid tumors. In particular, the use of this procedure in breast cancer has greatly reduced surgical treatment-related morbidity, reducing the number of patients submitted to unnecessary axillary dissection. It is also easy to perform and safe for patients and healthcare operators.

\section{Acknowledgments The authors thank Grainne Tierney for manu-} script editing.

Conflict of interest The authors certify that they have no financial or other conflicts of interest regarding the material discussed in the manuscript.
Ethical standard The study was performed in accordance with the ethical standards of the Declaration of Helsinki.

\section{References}

1. Kay Jamieson J, Dobson JF (1907) On the lymphatic system of the stomach. Lancet 169(4364):1061-1066

2. Gould EA, Winship T, Philbin PH, Kerr HH (1960) Observations on a "sentinel node" in cancer of the parotid. Cancer 13:77-78

3. Cabanas RM (1977) An approach for the treatment of penile carcinoma. Cancer 39(2):456-466

4. Krag DN, Weaver DL, Alex JC, Fairbank JT (1993) Surgical resection and radiolocalization of the sentinel lymph node in breast cancer using a gamma probe. Surg Oncol 2:335-339

5. Giuliano AE, Kirgan DM, Guenther JM, Morton DL (1994) Lymphatic mapping and sentinel lymphadenectomy for breast cancer. Ann Surg 220:391-398

6. Alex JC, Weaver DL, Fairbank JT, Rankin BS, Krag DN (1993) Gamma-probe-guided lymph node localization in malignant melanoma. Surg Oncol 2(5):303-308

7. De Cicco C, Cremonesi M, Luini A, Bartolomei M, Grana C, Prisco G, Galimberti V, Calza P, Viale G, Veronesi U, Paganelli G (1998) Lymphoscintigraphy and radioguided biopsy of the sentinel axillary node in breast cancer. J Nucl Med 39:2080-2084

8. Veronesi U, Paganelli G, Galimberti V, Viale G, Zurrida S, Bedoni M, Costa A, De Cicco C, Geraghty JG, Luini A, Sacchini V, Veronesi P (1997) Sentinel-node biopsy to avoid axillary dissection in breast cancer with clinically negative lymph-nodes. Lancet 349:1864-1867

9. Veronesi U, Paganelli G, Viale G, Luini A, Zurrida S, Galimberti $\mathrm{V}$ et al (2003) A randomized comparison of sentinel-node biopsy with routine axillary dissection in breast cancer. N Engl J Med 349:546-553

10. White RL, Wilke LG (2004) Update on the NSABP and ACOSOG breast cancer sentinel node trials. Am Surg 70(5):420-424

11. Krag DN, Julian TB, Harlow SP, Weaver DL, Ashikaga T, Bryant $\mathrm{J}$ et al (2003) NSABP-32: phase III, randomized trial comparing axillary resection with sentinal lymph node dissection: a description of the trial. Ann Surg Oncol 11(3):208S-210S

12. Luini A, Zurrida S, Galimberti V et al (1998) Radioguided surgery of occult breast lesions. Eur J Cancer 34(1):205-206

13. Paganelli G, Luini A, Veronesi U (2002) Radioguided occult lesion localization (ROLL) in breast cancer: maximizing efficacy, minimizing mutilation. Ann Oncol 13(12):1839-1840

14. Frank HA, Hall FM, Steer ML (1976) Preoperative localization of non-palpable breast lesions demonstrated by mammography. N Engl J Med 295:259-260

15. Acosta JA, Greenlee JA, Gubler KD et al (1995) Surgical margins after needle-localization breast biopsy. Am J Surg 170(6):643645

16. Lovrics PJ, Cornacchi SD, Farrokhyar F et al (2008) The relationship between surgical factors and margin status after breast conservation surgery for early stage breast cancer. Am J Surg 197(6):740-746

17. Gray RJ, Salud C, Nguyen K et al (2001) Randomized prospective evaluation of a novel technique for biopsy or lumpectomy of nonpalpable breast lesions: radioactive seed versus wire localization. Ann Surg Oncol 8(9):711-715

18. Gray RJ, Giuliano R, Dauway EL et al (2001) Radioguidance for non palpable primary lesions and sentinel lymph node(s). Am J Surg 182:404-406

19. Gray RJ, Pockaj BA, Karstaedt PJ et al (2004) Radioactive seed localization of nonpalpable breast lesions is better than wire localization. Am J Surg 188:377-380 
20. Hughes JH, Mason MC, Gray RJ et al (2008) A multi-site validation trial of radioactive seed localization as an alternative to wire localization. Breast J 14(2):153-157

21. Jakub JW, Gray RJ, Degnim AC et al (2010) Current status of radioactive seed for localization of non palpable breast lesions. Am J Surg 199:522-528

22. Bergqvist L, Strand S-E, Persson B (1983) Particle sizing and biokinetics of interstitial lympho-scintigraphic agents. Semin Nucl Med 12:9-19

23. Atkins HL, Hauser W, Richards P (1970) Factors affecting distribution of technetium-sulfur colloid. J Reticuloendothel Soc 8:176-184

24. Bergqvist L, Stundberg R, Ryden S, Strand S-E (1987) The, "critical colloid dose" in studies of reticuloendothelial function. J Nucl Med 28:1424-1429

25. Strand SE, Bergqvist L (1989) Radiolabeled colloids and macromolecules in the lymphatic system. Crit Rev Ther Drug Carrier Syst 6:211-218

26. Ikomi F, Hanna GK, Schmidt-Schonbein GW (1995) Mechanism of colloid uptake into the lymphatic system: basic study with percutaneous lymphography. Radiology 196:107-113

27. Eckelman WC, Steigman J, Paik CH (1996) Radiopharmaceutical chemistry. In: Harbert JC, Eckelman WC, Neumann RD (eds) Nuclear medicine-diagnosis and therapy. Thieme Medical Publishers, New York, pp 213-265

28. Tsopelas C (2001) Particles size analysis of ${ }^{99 \mathrm{~m}} \mathrm{Tc}$-labeled and unlabeled antimony trisulfide and rhenium sulfide colloids intended for lymphoscintigraphic application. J Nucl Med 42:460-466

29. Lovrics PJ, Cornacchi SD, Vora R, Goldsmith CH, Kahnamoui K (2011) Systematic review of radioguided surgery for non-palpable breast cancer. EJSO 37:388-397

30. Lin KM, Patel TH, Ray A, Ota M, Jacobs L, Kuvshinoff B et al (2004) Intradermal radioisotope is superior to peritumoral blue dye or radioisotope in identifying breast cancer sentinel nodes. J Am Coll Surg 199:561-566

31. Povoski SP, Olsen JO, Young DC, Clarke J, Burak WE, Walker MJ et al (2006) Prospective randomized clinical trial comparing intradermal, intraparenchymal, and subareolar injection routes for sentinel lymph node mapping and biopsy in breast cancer. Ann Surg Oncol 13:1412-1421

32. Rodier JF, Velten M, Wilt M, Martel P, Ferron G, Vaini-Elies V et al (2007) Prospective multicentric randomized study comparing periareolar and peritumoral injection of radiotracer and blue dye for the detection of sentinel lymph node in breast sparing procedures: FRANSENODE trial. J Clin Oncol 25:3664-3669

33. Noguchi M, Inokuchi M, Zen Y (2009) Complement of peritumoral and subareolar injection in breast cancer sentinel lymph node biopsy. J Surg Oncol 100:100-105

34. Argon AM, Duygun U, Acar E, Daglioz G, Yenjay L, Zekioglu O et al (2006) The use of periareolar intradermal Tc-99m tin colloid and peritumoral intraparenchymal isosulfan blue dye injections for determination of the sentinel lymph node. Clin Nucl Med $31: 795-800$

35. Suami H, Pan WR, Mann GB, Taylor GI (2008) The lymphatic anatomy of the breast and its implications for sentinel lymph node biopsy: a human cadaver study. Ann Surg Oncol 15:863-871

36. Krag DN, Anderson SJ, Julian TB, Brown AM, Harlow SP, Ashikaga $\mathrm{T}$ et al (2007) Technical outcomes of sentinel-lymphnode resection and conventional axillary-lymph-node dissection in patients with clinically node-negative breast cancer: results from the NSABP B-32 randomised phase III trial. Lancet Oncol 8:881-888

37. Tanis PJ, Valdes Olmos RA, Muller SH, Nieweg OE (2003) Lymphatic mapping in patients with breast carcinoma: reproducibility of lymphoscintigraphic results. Radiology 228:546-551

38. Gray RJ, Pockaj BA, Roarke MC (2004) Injection of (99m)Tclabeled sulfur colloid the day before operation for breast cancer sentinel lymph node mapping is as successful as injection the day of operation. Am J Surg 188:685-689

39. Babiera GV, Delpassand ES, Breslin TM, Ross MI, Ames FC, Singletary SE et al (2005) Lymphatic drainage patterns on early versus delayed breast lymphoscintigraphy performed after injection of filtered Tc-99m sulfur colloid in breast cancer patients undergoing sentinel lymph node biopsy. Clin Nucl Med 30:11-15

40. Buscombe J, Paganelli G, Burak ZE, Waddington W, Maublant J, Prats E et al (2007) Sentinel node in breast cancer procedural guidelines. Eur J Nucl Med Mol Imaging 34:2154-2159

41. Keidar Z, Israel O, Krausz Y (2003) SPECT/CT in tumor imaging: technical aspects and clinical applications. Semin Nucl Med 33:205-218

42. Lerman H, Metser U, Lievshitz G, Sperber F, Shneebaum S, Even-Sapir E (2006) Lymphoscintigraphic sentinel node identification in patients with breast cancer: the role of SPECT-CT. Eur J Nucl Med Mol Imaging 33:329-337

43. van der Ploeg IM, Nieweg OE, Kroon BB, Rutgers EJ, BaasVrancken Peeters MJ, Vogel WV et al (2009) The yield of SPECT/CT for anatomical lymphatic mapping in patients with breast cancer. Eur J Nucl Med Mol Imaging 36:903-909

44. Vermeeren L, van der Ploeg IM, Valdes Olmos RA, Meinhardt W, Klop WM, Kroon BB et al (2010) SPECT/CT for preoperative sentinel node localization. J Surg Oncol 101:184-190

45. Giammarile F, Alazraki N, Aarsvold JN, Audisio RA, Glass E, Grant SF, Kunikowska J, Leidenius M, Moncayo VM, Uren RF, Oyen WJG, Valdés Olmos RA, Sicart SV (2013) The EANM and SNMMI practice guideline for lymphoscintigraphy and sentinel node localization in breast cancer. Eur J Nucl Med Mol Imaging 40:1932-1947

46. Kaufmann M, Morrow M, von Minckwitz G, Harris JR, Biedenkopf Expert Panel Members (2010) Locoregional treatment of primary breast cancer: consensus recommendations from an International Expert Panel. Cancer 116:1184-1191

47. Lyman GH, Temin S, Edge SB, Newman LA, Turner RR, Weaver DL, Benson AB III, Bosserman LD, Burstein HJ, Cody H III, Hayman J, Perkins CL, Podoloff DA, Giuliano AE (2014) Sentinel lymph node biopsy for patients with early-stage breast cancer: American Society of Clinical Oncology clinical practice guideline update. J Clin Oncol 32:1365-1383

48. Zavagno G, De Salvo GL, Scalco G, Bozza F, Barutta L, Del Bianco P, Renier M, Racano C, Carraro P, Nitti D, GIVOM Trialists (2008) A randomized clinical trial on sentinel lymph node biopsy versus axillary lymph node dissection in breast cancer: results of the Sentinella/GIVOM trial. Ann Surg 247(2):207-213

49. Veronesi U, Viale G, Paganelli G, Zurrida S, Luini A, Galimberti $\mathrm{V}$, Veronesi $\mathrm{P}$, Intra $\mathrm{M}$, Maisonneuve $\mathrm{P}$, Zucca $\mathrm{F}$, Gatti G, Mazzarol G, De Cicco C, Vezzoli D (2010) Sentinel lymph node biopsy in breast cancer: ten-year results of a randomized controlled study. Ann Surg 251(4):595-600

50. Krag DN, Anderson SJ, Julian TB, Brown AM, Harlow SP, Costantino JP, Ashikaga T, Weaver DL, Mamounas EP, Jalovec LM, Frazier TG, Noyes RD, Robidoux A, Scarth HM, Wolmark N (2010) Sentinel-lymph-node resection compared with conventional axillary-lymph-node dissection in clinically nodenegative patients with breast cancer: overall survival findings from the NSABP B-32 randomised phase 3 trial. Lancet Oncol 11(10):927-933

51. Giuliano AE, Hunt KK, Ballman KV et al (2011) Axillary dissection vs no axillary dissection in women with invasive breast 
cancer and sentinel node metastasis: a randomized clinical trial. JAMA 305:569-575

52. Galimberti V, Cole BF, Zurrida S et al (2013) Axillary dissection versus no axillary dissection in patients with sentinel-node micrometastases (IBCSG 23-01): a phase 3 randomised controlled trial. Lancet Oncol 14:297-305

53. National Comprehensive Cancer Network (NCCN) (2014) NCCN clinical practice guidelines in oncology breast cancer, Version 1.2014

54. Goldhirsch A, Wood WC, Coates AS, Gelber RD, Thürlimann B, Senn HJ, Panel members (2011) Strategies for subtypes-dealing with the diversity of breast cancer: highlights of the St. Gallen International expert consensus on the primary therapy of early breast cancer 2011. Ann Oncol 22:1736-1747

55. Zujewski J, Eng-Wong J (2005) Sentinel lymph node biopsy in the management of ductal carcinoma in situ. Clin Breast Cancer 6:216-222

56. Sakr R, Bezu C, Raoust I, Antoine M, Ettore F, Darcourt J et al (2008) The sentinel lymph node procedure for patients with preoperative diagnosis of ductal carcinoma in situ: risk factors for unsuspected invasive disease and for metastatic sentinel lymph nodes. Int J Clin Pract 62:1730-1735

57. Sakr R, Antoine M, Barranger E, Dubernard G, Salem C, Darai E et al (2008) Value of sentinel lymph node biopsy in breast ductal carcinoma in situ upstaged to invasive carcinoma. Breast $\mathbf{J}$ $14: 55-60$

58. Intra M, Rotmensz N, Veronesi P, Colleoni M, Iodice S, Paganelli $G$ et al (2008) Sentinel node biopsy is not a standard procedure in ductal carcinoma in situ of the breast: the experience of the European Institute of Oncology on 854 patients in 10 years. Ann Surg 247:315-319

59. Ansari B, Ogston SA, Purdie CA, Adamson DJ, Brown DC, Thompson AM (2008) Meta-analysis of sentinel node biopsy in ductal carcinoma in situ of the breast. Br J Surg 95:547-554

60. Taback B, Nguyen P, Hansen N, Edwards GK, Conway K, Giuliano AE (2006) Sentinel lymph node biopsy for local recurrence of breast cancer after breast-conserving therapy. Ann Surg Oncol 13:1099-1104

61. Port ER, Garcia-Etienne CA, Park J et al (2007) Reoperative sentinel lymph node biopsy: a new frontier in the management of ipsilateral breast tumor recurrence. Ann Surg Oncol 14:2209-2214

62. Cox CE, Furman BT, Kiluk JV et al (2008) Use of reoperative sentinel lymph node biopsy in breast cancer patients. J Am Coll Surg 207:57-61

63. Kaur P, Kiluk JV, Meade T et al (2011) Sentinel lymph node biopsy in patients with previous ipsilateral complete axillary lymph node dissection. Ann Surg Oncol 18:727-732
64. Gentilini O, Cremonesi M, Trifirò G et al (2004) Safety of sentinel node biopsy in pregnant patients with breast cancer. Ann Oncol 15:1348-1351

65. Mondi MM, Cuenca RE, Ollila DW et al (2007) Sentinel lymph node biopsy during pregnancy: initial clinical experience. Ann Surg Oncol 14:218-221

66. Steenvoorde P, Pauwels EK, Harding LK et al (1998) Diagnostic nuclear medicine and risk for the fetus. Eur $\mathrm{J}$ Nucl Med 25:193-199

67. Donegan WL (1977) The influence of untreated internal mammary metastases upon the course of mammary cancer. Cancer 39:533-538

68. Veronesi U, Cascinelli N, Bufalino R, Morabito A, Greco M, Galluzzo D, Delle Donne V, De Lellis R, Piotti P, Sacchini V et al (1983) Risk of internal mammary lymph node metastases and its relevance on prognosis of breast cancer patients. Ann Surg 198(6):681-684

69. Cody HS 3rd, Urban JA (1995) Internal mammary node status: a major prognosticator in axillary node-negative breast cancer. Ann Surg Oncol 2:32-37

70. Sugg SL, Ferguson DJ, Posner MC et al (2000) Should internal mammary nodes be sampled in the sentinel lymph node era? Ann Surg Oncol 7:188-192

71. Veronesi U, Marubini E, Mariani L, Valagussa P, Zucali R (1999) The dissection of internal mammary nodes does not improve the survival of breast cancer patients. 30-year results of a randomised trial. Eur J Cancer 35:1320-1325

72. Leidenius MH, Krogerus LA, Toivonen TS, Leppänen EA, von Smitten KA (2006) The clinical value of parasternal sentinel node biopsy in breast cancer. Ann Surg Oncol 13:321-326

73. Ahmed M, Douek M (2013) Sentinel node and occult lesion localization (SNOLL): a systematic review. Breast 22:1034-1040

74. Rescigno J, Zampell JC, Axelrod D (2009) Patterns of axillary surgical care for breast cancer in the era of sentinel lymph node biopsy. Ann Surg Oncol 16:687-696

75. Leong SP, Shen ZZ, Liu TJ et al (2010) Is breast cancer the same disease in Asian and Western countries? World J Surg 34:2308-2324

76. Ahmed M, Purushotham AD, Douek M (2014) Novel techniques for sentinel lymph node biopsy in breast cancer: a systematic review. Lancet Oncol 15:351-362

77. Thill M, Kurylcio A, Welter R, van Haasteren V, Grosse B, Berclaz G, Polkowski W, Hauser N (2014) The Central-European SentiMag study: sentinel lymph node biopsy with superparamagnetic iron oxide (SPIO) vs. radioisotope. Breast 23:175-179 